\title{
Is simulation the next best thing?
}

\author{
K. Annette Mizuguchi, MD, PhD, MMSc
}

See related article on pages 22-5.

Trainees today are struggling with acquiring the skills and knowledge necessary to become a competent physician while accomplishing this task within the framework of the work hour rules. Meanwhile, budget cuts in medicine demand increased clinical productivity. Thus educators today need innovative learning methods to help learners learn, via Web-based learning methods, which encompasses all educational interventions that use the internet or intranet through online tutorials, online discussion groups, virtual patients, or simulation. ${ }^{1}$ In addition, academic physicians need educational research data to guide and help students to learn in the most efficient and effective manner.

In this issue of the Journal of Thoracic and Cardiovascular Surgery, Smelt and colleagues ${ }^{2}$ present a study on the impact of simulation-based teaching versus traditional teaching on the ability of cardiac surgical trainees to recognize transesophageal echocardiographic (TEE) images. Although simulation-based teaching for learning transesophageal echocardiographic views is not new and the sample size of the trainees studied was small, Smelt and colleagues ${ }^{2}$ were able to demonstrate a learning effect, as evidenced by an improvement in posttest scores relative to pretest scores.

In this study, Smelt and colleagues ${ }^{2}$ randomly assigned a group of trainees to receive simulation-based teaching versus a control group who received intraoperative TEE teaching during an elective TEE rotation. Both groups learned the standard TEE views during the allotted time. Trainees in the simulation group studied TEE images obtained with a TEE simulator, and trainees in the control group studied images recorded in the operating room in an anesthetized patient undergoing elective coronary artery bypass. Both groups were assessed with the same pretest and posttest.

There are several weaknesses in this study. One weakness lies in the design of the study. A pretest-posttest study is a simple method of testing the effectiveness of an intervention. With this design, however, it is unclear whether the

From the Division of Perioperative and Pain Medicine, Department of Anesthesiology, Brigham and Women's Hospital, Harvard Medical School, Boston, Mass. Disclosures: Author has nothing to disclose with regard to commercial support. Received for publication April 30, 2015; accepted for publication May 1, 2015

Address for reprints: K. Annette Mizuguchi, MD, PhD, MMSc, Department of Anesthesiology, Brigham and Women's Hospital, 75 Francis St, CWN-L1, Boston, MA 02115 (E-mail: amizuguchi@partners.org).

J Thorac Cardiovasc Surg 2015;150:26-7

$0022-5223 / \$ 36.00$

Copyright (c) 2015 by The American Association for Thoracic Surgery

http://dx.doi.org/10.1016/j.jtcvs.2015.05.004 pretest alone resulted in the learning effect (pretest sensitization), or if the intervention (simulation vs intraoperative teaching) resulted in the learning effect, or if the learning effect was a result of a combination of both factors. ${ }^{3}$

Second, prior knowledge of their trainees in the groups may have differed even though both

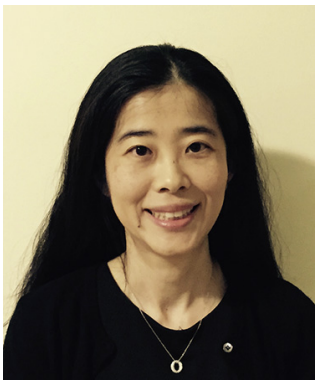
performed similarly on their pretests. Third, because of the small sample size, Smelt and colleagues $^{2}$ were unable to determine whether the simulation approach was superior to the intraoperative teaching approach. Finally, Smelt and colleagues ${ }^{2}$ only tested their trainees during a single session and did not ascertain the benefit of distributed practice or spaced education, where "spaced effect" refers to the finding that learning and retention of learned material is more effective when presented and repeated during spaced intervals. ${ }^{4,5}$

The strength of this article is that Smelt and colleagues 2 were able to demonstrate a learning effect in both the simulation and traditional intraoperative groups. This has potential beneficial implications. First, this suggests that cardiac surgical trainees in a busy practice may be able to learn the TEE images off-line (out of the operating room) with a TEE simulator. Second, although Smelt and colleagues ${ }^{2}$ only studied the benefit of a "once only" teaching method, use of simulation could easily be incorporated into a learning program that spaces study activities through time (distributed practice). ${ }^{4}$ Finally, even though Smelt and colleagues ${ }^{2}$ were unable to show that simulation-based teaching was not superior to traditional teaching, they were clearly able to demonstrate a learning effect with both methods. This may suggest that teaching of any type is still worth the effort.

In summary, this study is timely, because all of us are dealing with educating our trainees within the constraints of the work hour rules. Although web-based (computer and simulation) learning will not replace every aspect of clinical education, a balance of traditional teaching and new technology is probably the foundation of education moving forward.

\section{References}

1. Cook DA. Web-based learning: pros, cons and controversies. Clin Med. 2007;7: $37-42$.

2. Smelt J, Corredor C, Edsell M, Fletcher N, Jahangiri M, Sharma V. Simulationbased learning of transesophageal echocardiography in cardiothoracic surgical trainees: A prospective, randomized study. J Thorac Cardiovasc Surg. 2015; 150:22-5.

3. Kim ES, Willson VL. Evaluating pretest effects in pre-post studies. Educ Psychol Meas. 2010;70:744-59. 
4. Kerfoot BP, Fu Y, Baker H, Connelly D, Ritchey ML, Genega EM. Online spaced education generates transfer and improves long-term retention of diagnostic skills: a randomized controlled trial. J Am Coll Surg. 2010;211: 331-7.e1.
5. Dunlosky J, Rawson KA, Marsh EJ, Nathan MJ, Willingham DT. Improving Students' Learning with Effective Learning Techniques: Promising Directions from Cognitive and Educational Psychology. Assoc Psychol Sci. 2013;14: 4-58. 